\title{
IMPACTO DO RUÍDO DE TRÁFEGO: ESTUDO DE CASO NO BAIRRO DE LAGOA NOVA, NATAL-RN
}

\author{
IMPACT OF TRAFFIC NOISE: CASE STUDY IN LAGOA NOVA, NATAL-RN
}

\author{
Débora Nogueira Pinto ${ }^{1}$, Virgínia Maria Dantas de Araújo ${ }^{2}$, Bianca Carla Dantas de Araújo ${ }^{3}$, \\ Renato Nascimento Gomes ${ }^{4}$
}

Recebido em 12 de fevereiro de 2012; recebido para revisão em 16 de fevereiro de 2013; aceito em 17 de fevereiro de 2013; disponível on-line em 28 de fevereiro de 2013.

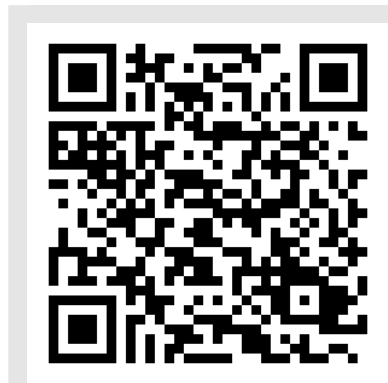

PALAVRAS CHAVE:

Conforto acústico urbano;

Ruído de tráfego;

Poluição sonora.

KEYWORDS:

Urban acoustic comfort;

Traffic noise;

Noise Pollution.

RESUMO: A poluição sonora provoca uma degradação na qualidade do meio ambiente e se apresenta como um dos problemas ambientais mais frequentes nas grandes cidades. São inúmeras as fontes sonoras, e ruído gerado pelo trânsito é o mais comum. Desta forma, este trabalho objetiva realizar uma análise de ruído de tráfego em um bairro da cidade de Natal/RN, tendo em vista que o mesmo está passando atualmente por modificações no espaço urbano devido à construção do novo estádio para a Copa do Mundo FIFA de futebol em 2014. Foi realizada a contagem classificada dos veículos (leves e pesados) e medição do nível de pressão sonora Leq ( $\mathrm{dBA}$ ) em 14 pontos de medição, no horário da manhã (7hs às 8hs) e no horário noturno (20hs às $21 \mathrm{hs}$ ), totalizando 6 medições de 10 minutos por ponto. Como resultado observou-se a correlação fortemente positiva entre o volume de tráfego e o Leq (dBA) medido. As medições de nível de pressão sonora em campo revelaram também que os níveis de ruído estão acima do recomendado pelas normas em todos pontos medidos, e há vias com saturação viária com relação ao volume de veículos.

\begin{abstract}
Noise pollution degrade the quality of the environment and presents itself as one of the most common environmental problems in large cities. There are numerous sources, and noise generated by traffic is the most common. Thus, this study aims to conduct a traffic noise in a neighborhood of the city of Natal / RN, in order that it is currently undergoing modifications in urban areas due to the construction of the new stadium for the FIFA World Cup football in 2014. Were counted rated vehicles (light and heavy) and measurement of sound pressure level Leq (dBA) at 14 measurement points in the morning hours ( $7 \mathrm{am}$ to $8 \mathrm{am}$ ) and nighttime (20pm to $21 \mathrm{pm})$, totaling six measurement point for 10 minutes. As a result there was a strong positive correlation between the volume of traffic and Leq (dBA) measured. Measurements of sound pressure level in the field have also revealed that noise levels are above the recommended standards in all measured points, and there are roads with road saturation with respect to the volume of vehicles.
\end{abstract}

\footnotetext{
* Contato com os autores:
}

${ }^{1}$ e-mail : deboranpinto@gmail.com

(D. N. Pinto)

Mestranda do Programa de Pós-Graduação em Arquitetura e Urbanismo da Universidade Federal do Rio Grande do Norte (UFRN)

2e-mail : virginia@ufrnet.br (V. M. D. de Araújo)

Professora Dra. do Programa de Pós-Graduação em Arquitetura e Urbanismo da Universidade Federal do Rio Grande do Norte (UFRN)

3 e-mail : dantasbianca@gmail.com

(B. C. D. de Araújo)

Professora Dra. do Programa de Pós-Graduação em Arquitetura e Urbanismo da Universidade Federal do Rio Grande do Norte (UFRN)

${ }^{4}$ e-mail : renatogomes_rn@hotmail.com (R. N. Gomes)

Graduando do curso de Árquitetura e Urbanismo da Universidade Federal do Rio Grande do Norte (UFRN) 


\section{INTRODUÇÃO}

A poluição sonora provoca uma degradação na qualidade do meio ambiente e se apresenta como um dos problemas ambientais mais frequentes nas grandes cidades. Vários estudos mostram os malefícios que a exposição ao ruído pode trazer ao ser humano, interferindo diretamente na saúde psicológica e fisiológica. Na escala urbana é uma das principais causas de desvalorização de residências localizadas em zonas centrais, podendo modificar até mesmo a organização da cidade, interferindo na sua distribuição e no seu crescimento (MARCELO, 2006).

São inúmeras as fontes sonoras como os aviões, trens, veículos, construções, indústrias, comércios e serviços. O ruído gerado pelo trânsito é o mais comum e com o desenvolvimento do setor se tornou o maior problema para o conforto acústico urbano. Vale ressaltar também que o ruído de tráfego é composto pela sobreposição de ruídos de muitos veículos, além das distintas condições dos mesmos (MENDEZ, 1994). Segundo Bistafa (2006), o ruído de tráfego constitui uma das principais fontes de poluição ambiental, podendo este ser de tráfego rodoviário, ferroviário, aéreo. Com o desenvolvimento da sociedade, ocorre um aumento do grau de urbanização e industrialização, e consequentemente da extensão da malha de transporte. Sendo assim, cada um desses fatores contribui para o aumento da poluição sonora em áreas urbanas, a intensidade do som resultantes do tráfego depende de vários fatores, tais como: tipo, qualidade e velocidade dos veículos; qualidade da pavimentação; fluxo do tráfego, com aceleração e desaceleração; características dos pneus de carros (MOTA, 1981).

Segundo Bistafa (2006), o ruído de tráfego constitui uma das principais fontes de poluição ambiental, podendo este ser de tráfego rodoviário, ferroviário, aéreo. Com o desenvolvimento da sociedade, ocorre um aumento do grau de urbanização e industrialização, e consequentemente da extensão da malha de transporte. Sendo assim, cada um desses fatores contribui para o aumento da poluição sonora. Em áreas urbanas, a intensidade do som resultantes do tráfego depende de vários fatores, tais como: tipo, qualidade e velocidade dos veículos; qualidade da pavimentação; fluxo do tráfego, com aceleração e desaceleração; características dos pneus de carros (MOTA, 1981).

Em geral, o que se observa é que o excesso de ruído urbano está associado à explosão demográfica das cidades, juntamente com a falta de uma política urbana e de aplicação de normas que controlem os níveis de emissão de ruído de tráfego (SANCHO; SENCHERMES, 1983). Desta forma, o mapeamento de ruído é uma importante ferramenta de planejamento urbano que apresenta uma informação visual do comportamento acústico de uma área geográfica, em um determinado momento (PINTO; MORENO, 2008). Consiste na medição do nível de ruído nas ruas, ajudando a identificar áreas com níveis sonoros acima dos permitidos, bem como as fontes emissoras. Com os mapas também é possível se pensar em diferentes cenários futuros e prever o impacto de novas estruturas e atividades no local estudado. Assim, apresenta a possibilidade de construção de um plano de ação para controle do ruído e ajuda no estabelecimento de legislações, promovendo uma melhoraria na qualidade de vida das pessoas.

\section{OBJETIVOS}

Este trabalho objetiva uma análise de ruído de tráfego no bairro de Lagoa Nova em Natal/RN, tendo em vista que o bairro em estudo está passando atualmente por grandes mudanças no espaço urbano devido à construção do novo estádio para a Copa do Mundo FIFA de Futebol em 2014 e as obras de mobilidade urbana previstas para o entorno da área.

\section{O BAIRRO DE LAGOA NOVA}

A cidade de Natal/RN possui uma configuração espacial que se aproxima ao recorte geográfico de uma figura triangular, com seu vértice localizado no encontro entre o Oceano Atlântico e a desembocadura do estuário do Potengi/Jundiaí, aonde começou o povoamento da Cidade. Espalhou-se gradativamente, com um crescimento natural em direção ao Sul, pois os elementos naturais (o parque das Dunas, o Rio Potengi e o Oceano Atlântico) dificultaram significativamente outra forma de expansão. Posteriormente o povoamento deuse atravessando o Rio Potengi/ Jundiaí em direção ao Norte (MACEDO, 2005). O Bairro de Lagoa Nova (Figura 1) encontra-se no caminho desse crescimento, em uma área de centralidade da cidade e de passagem entre as zonas, está localizado na região administrativa sul da cidade de Natal/RN.

O bairro de Lagoa Nova começou a se desenvolver no início da década de 60, com a criação de conjuntos habitacionais que deram impulso à aglomeração. Está situado na "zona adensável" da 
apresentando um total de $73,23 \%$ de imóveis residenciais (SEMURB, 2008). Possui três avenidas de grande importância para a cidade, que ao longo delas o comércio e serviço são as atividades principais - Av. Senador Salgado Filho, Av. Prudente de Morais e Av. Bernardo Vieira.

O Bairro abrigava também o antigo estádio de futebol, o João Machado (Machadão), que foi demolido juntamente com o ginásio Machadinho, para a construção do novo estádio (Arena das Dunas) para a Copa do Mundo de 2014. O entorno do estádio apresenta uma área de intenso tráfego e com tendência a saturação viária, com a proximidade das duas avenidas de maior fluxo da cidade, a Av. Senador Salgado Filho e a Av. Prudente de Morais. Assim, a área de estudo escolhida corresponde ao entorno do estádio Arena das Dunas (Figura 2).

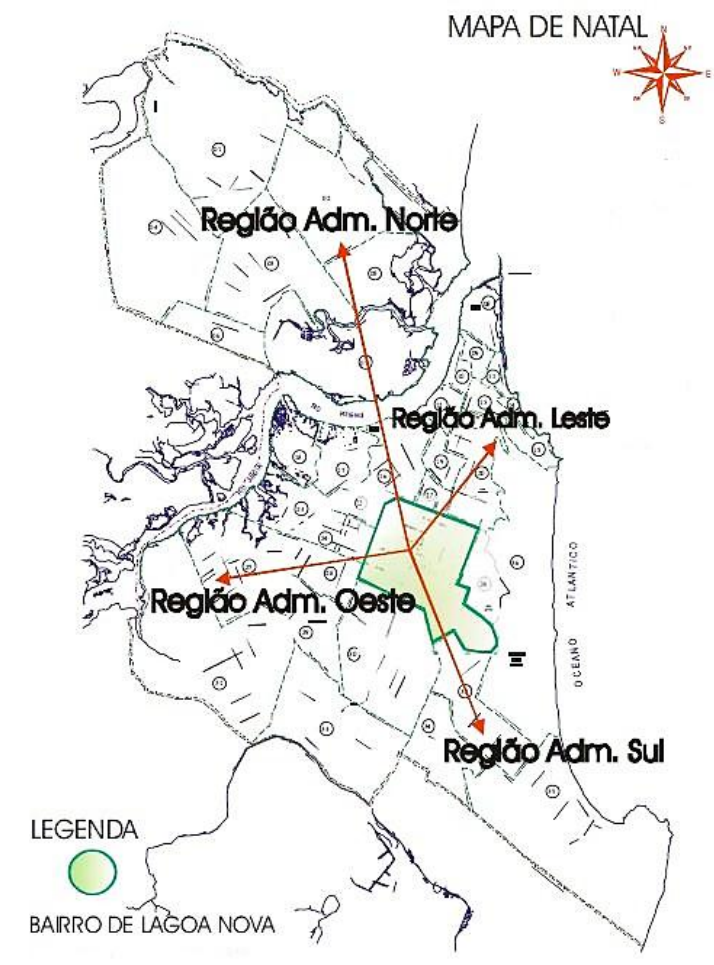

Fonte: Macedo, 2005.

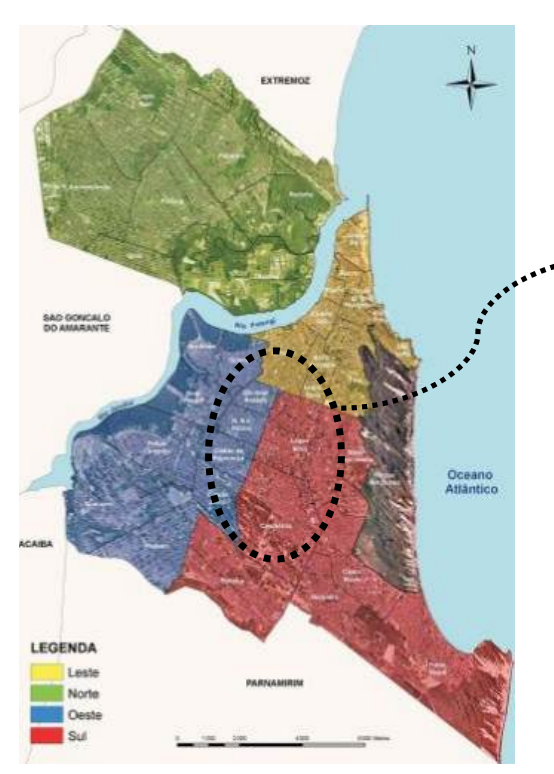

(a)

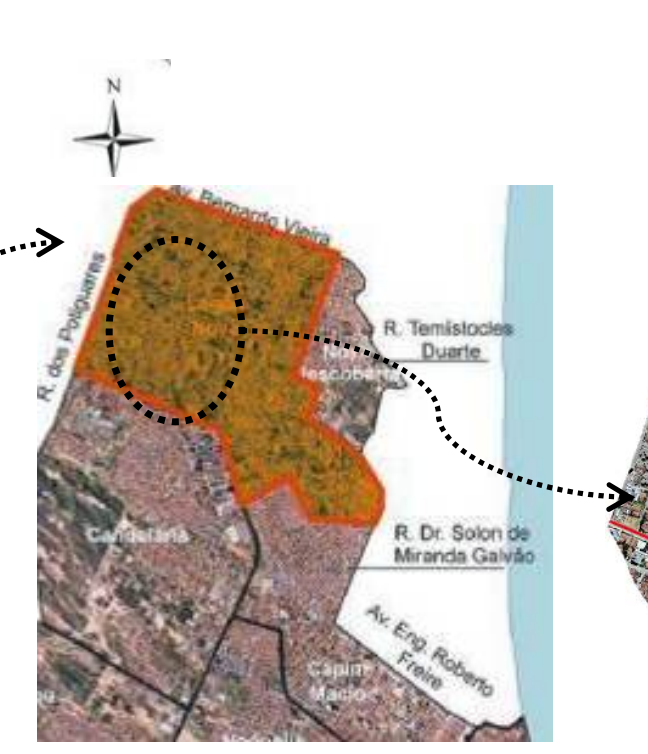

(b)

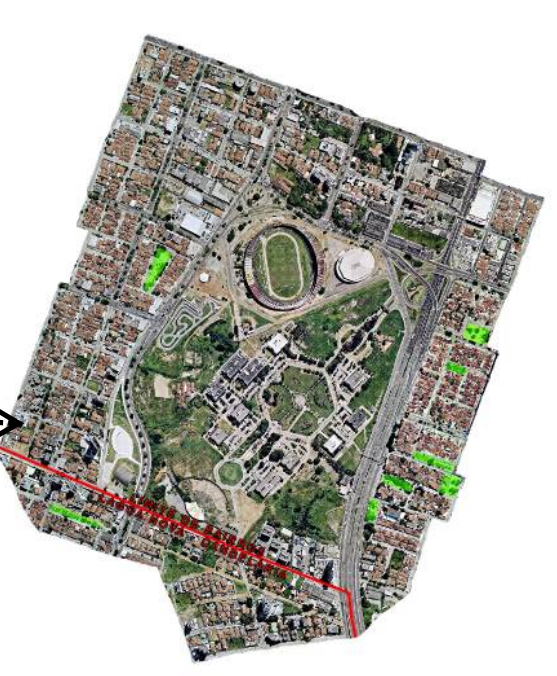

(c)

Figura 2: (a) Mapa de Natal com regiões administrativas; (b) Mapa da zona sul de Natal com destaque para o bairro de Lagoa Nova; (c) Mapa da Área de estudo. Fonte: SEMURB (2008), modificado. 


\section{MATERIAIS E MÉTODOS}

As medições de ruído de tráfego foram realizadas em 14 pontos do bairro. Sendo 4 vias arteriais e 3 coletoras e 7 vias locais (Figura 3). Durante esse período também foi contabilizado o fluxo de veículos.

Para a análise do ruído ambiental da área foram realizadas medições de ruído de tráfego, bem como a contagem de do fluxo de veículos. Foram realizadas em 14 pontos (figura 4), nos períodos diários de 07:00hs às 08:00hs e de 20:00 às 21:00, durante 10min, nos dias de semana típicos, sem interferências de chuvas e padrão normal de trânsito, foram realizadas três medições em cada ponto, totalizando 6 medições de 10 minutos por ponto. Cabe ressaltar que o ponto 35 corresponde ao Centro Administrativo do Município de Natal, no qual encontra-se fechado no período Noturno.

o medidor utilizado para os registros/medições da pressão sonora foi o Medidor de Nível Sonoro da marca 01dB, modelo SOLO SLM, Tipo 2. $\mathrm{O}$ equipamento possui recursos de medição de nível de pressão sonora equivalentes (LAeq), conforme a IEC 60804, medições paralelas de nível de pressão sonora (com 1 ponderação temporal): Start / Stop, 30-140 dBA em um único range. Possui ainda filtro de bandas de oitavas (1/1) em tempo real $(16 \mathrm{~Hz}-16 \mathrm{kHz})$ - média, mínimo, máximo, e filtro de bandas de oitavas (1/3) em tempo real $(12,5 \mathrm{~Hz}-20 \mathrm{kHz})$ - média, mínimo, máximo.

O medidor de nível sonoro foi posicionado, segundo a NBR 10151(ABNT,2000), a 1,2m do chão e a $2 \mathrm{~m}$ das edificações, quando possível, em direção aos ventos dominantes, para não criar barreira. Nos canteiros o aparelho foi posicionado no seu alinhamento para captar o ruído nos dois sentidos da via. Já nas calçadas foi colocado perpendicularmente à via. As medições foram realizadas sempre nas áreas entre os semáforos para evitar a aceleração ou desaceleração dos veículos.

Foram registrados os dados de Leq - Nível de Pressão Sonoro Equivalente (por freqüência em bandas de $1 / 3$ de oitava). Os níveis de pressão sonoras foram medidos na escala $A$, expressa em $d B(A)$ e utilizou-se a indicação de resposta lenta do medidor, conforme as Normas Técnicas adotadas. O equipamento está aferido dentro dos padrões requeridos para o ensaio.

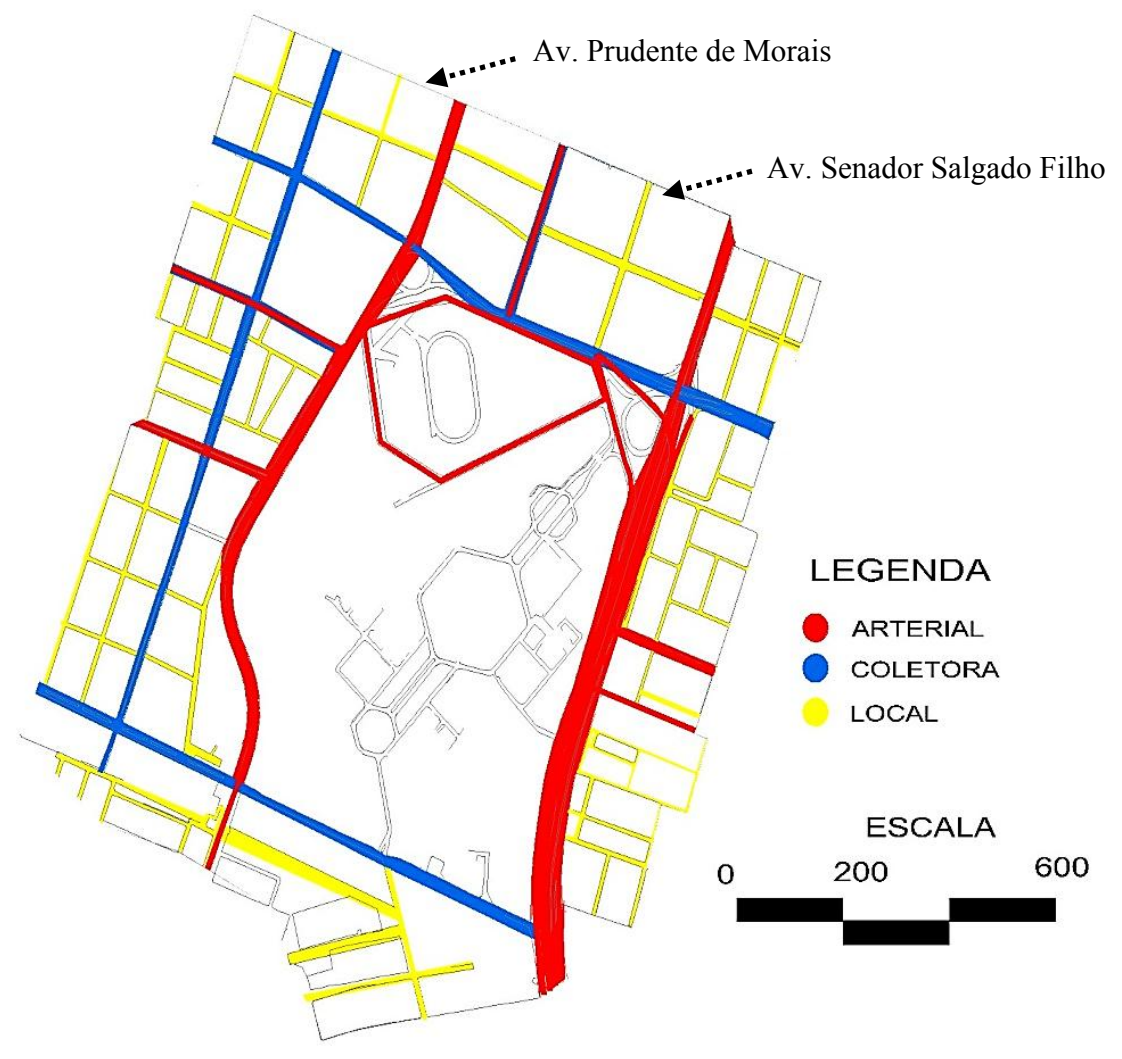

Figura 3: Mapa hierarquia de vias. 


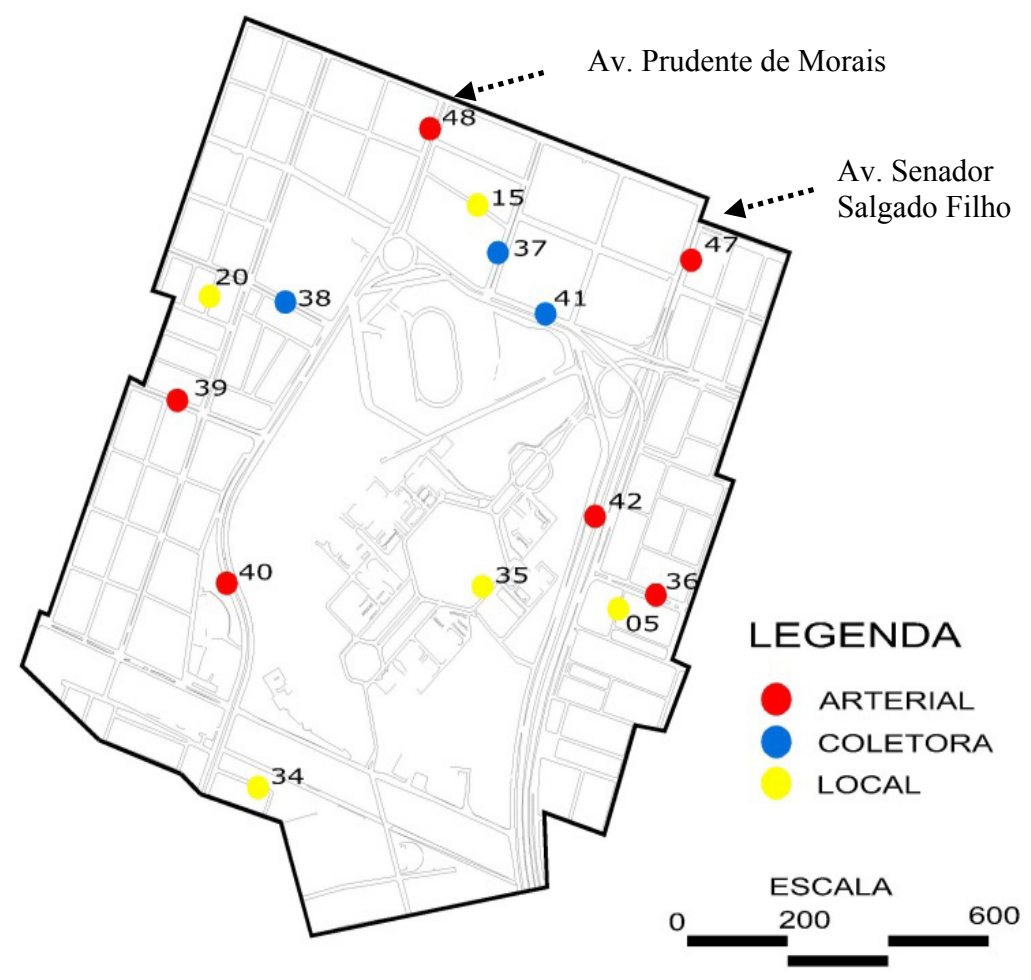

Figura 4: Mapa com localização dos pontos de medição.

\section{RESULTADOS E DISCUSSÕES}

De acordo com a NBR 10151 (ABNT, 2000), o bairro estudado, considerado uma área mista, predominantemente residencial, o Nível Critério de Avaliação (NCA) para ambientes externos é de $55 \mathrm{~dB}(\mathrm{~A})$ no período diurno e $50 \mathrm{~dB}$ (A) no período diurno. Considerando a média aritmética dos dados coletados em relação ao nível de pressão sonora, observa-se pelos dados levantados, que no período Diurno e Noturno todos os pontos medidos nas vias locais apresentaram níveis fora dos recomendados pela referida norma (Figura 5).
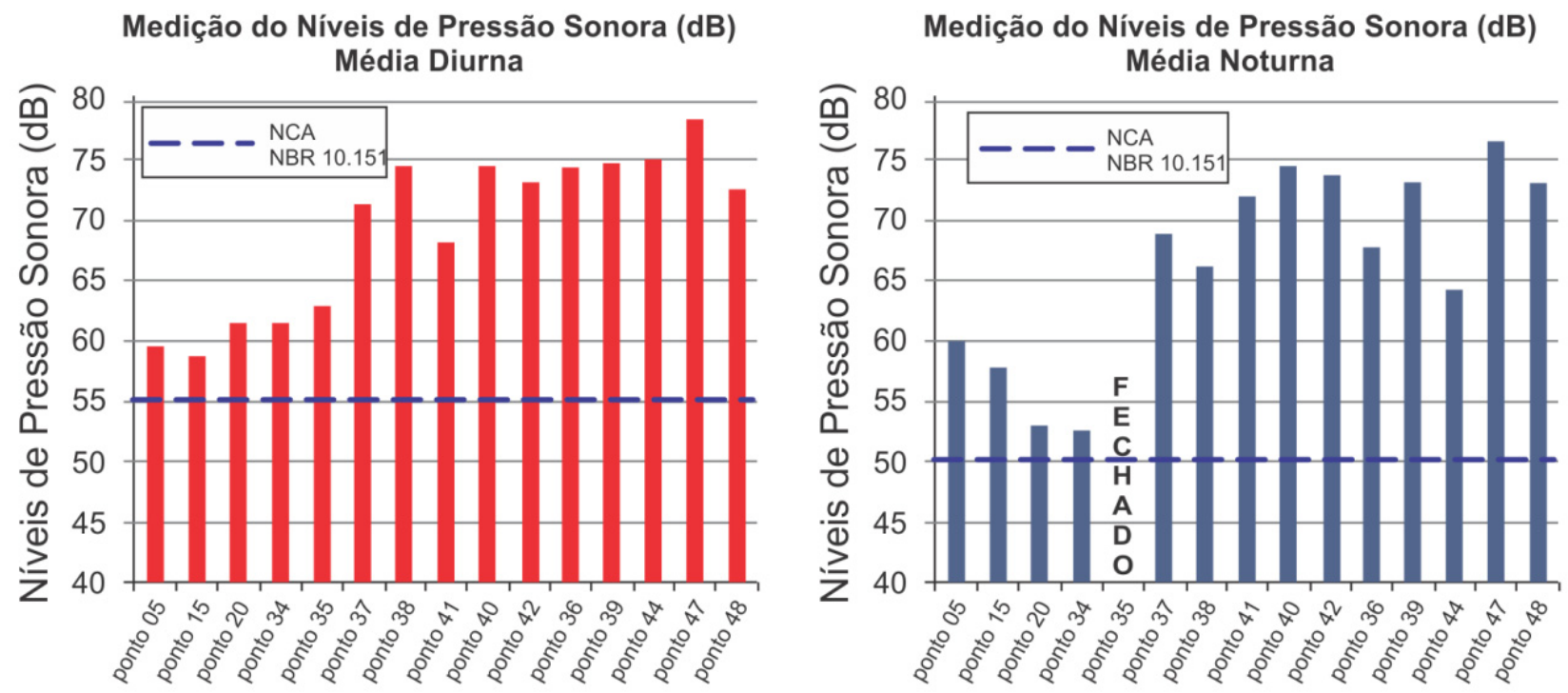

Figura 5: Relação de Nível de Pressão Sonora (Leq dBA) por pontos de medição. 
Outro parâmetro analisado foi com relação às diferenças realizadas no mesmo ponto, sendo 3 no período diurno e 3 no período Noturno. Foi verificado um desvio padrão máximo de 5,45, ocorrendo no período diurno as maiores variações dos dados medidos. Com o objetivo de obter dados mais fidedignos, essa variação mostra a importância de se realizar mais de uma medição por ponto (Figura 6).

Em relação à contagem dos veículos, percebese que as avenidas arteriais são as que possuem maior fluxo de veículos e possuem também uma maior presença de edifícios comerciais e de serviços, consequentemente são as vias com maiores níveis de ruído. Com a contagem classificada de veículos (considerando leves como automóveis e utilitários e pesados sendo caminhões, ônibus, e excepcionalmente motos, devido o nível de pressão sonora produzido) é possível verificar a relação direta entre o nível de pressão sonora medido em $\mathrm{dB}(\mathrm{A})$ com o volume de tráfego.

Com relação ao período noturno, nenhum dos pontos medidos apresentaram os dados dentro dos níveis exigidos pela referida norma . Comparando com o período diurno, percebe-se uma redução de fluxo de veículos de: $84 \%$ nas ruas locais (P5, P15, P34, P35), 74\% nas avenidas coletoras (P37, P38, P44), P41 e 49\% nas avenidas arteriais (P36, P39, P40, P42, P47, P48). Com os dados levantados é possível verificar a grande diferença que o fluxo de tráfego provoca no nível de pressão sonora, no qual as avenidas arteriais e coletoras apresentam nível de pressão sonora equivalentes bem maiores que as ruas locais (Figura 7).
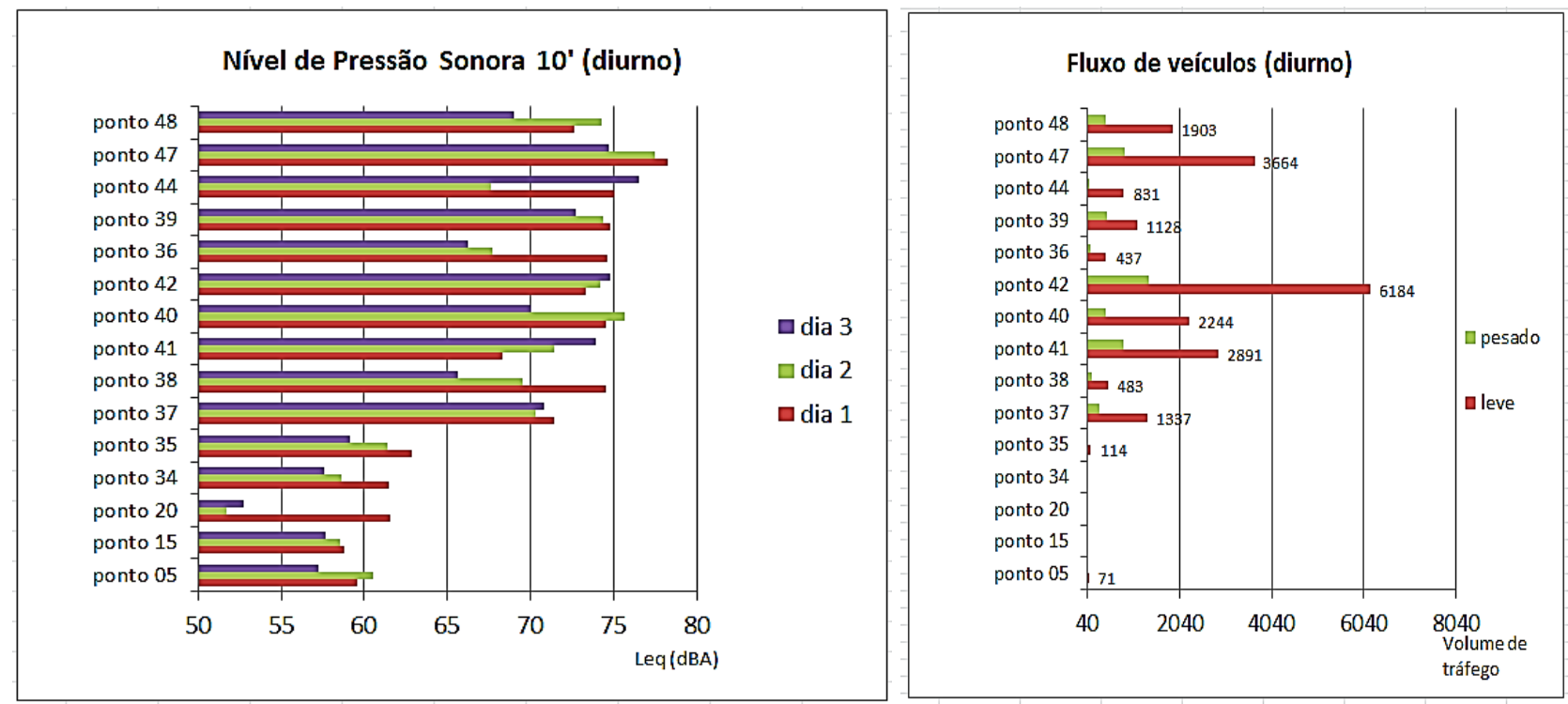

Figura 6: Nível de Pressão Sonora (Leq dBA) e fluxo de veículos, por pontos e dias de medição, diurno.
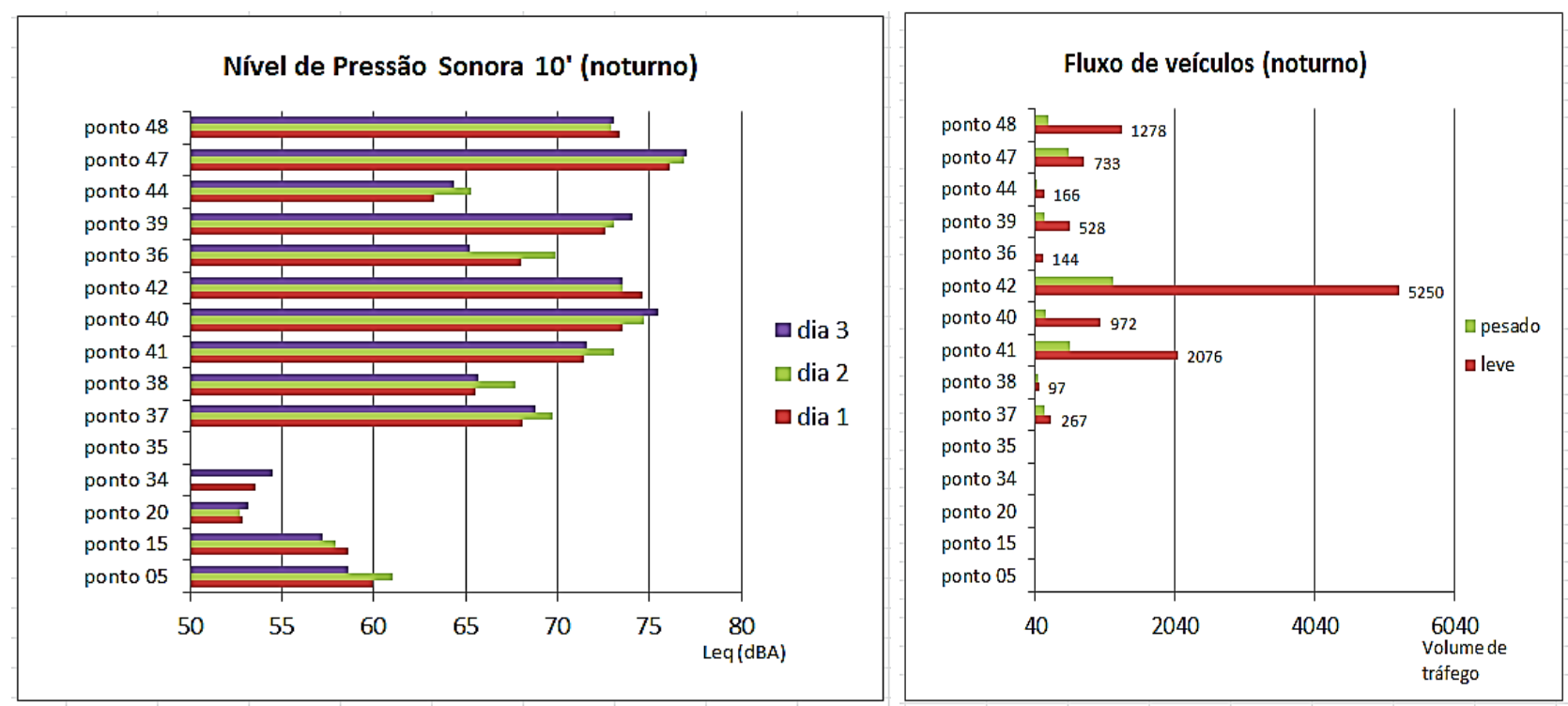

Figura 7: Nível de Pressão Sonora (Leq dBA) e fluxo de veículos, por pontos e dias de medição, noturno. 
As divergências ainda evidenciam-se quando são analisados os espectros do menor nível de pressão sonora medido nas vias locais, e do maior nível medido nas vias arteriais. Pode-se observar que nas vias locais (Figura 8) os níveis sonoros apresentam energia com maior concentração nas baixas frequências (até aproximadamente $200 \mathrm{~Hz}$ ), enquanto nas vias arteriais (Figura 9) essa energia é encontrada com valores significativos até $2000 \mathrm{~Hz}$.

Com a contagem classificada de veículos (considerando leves como automóveis e utilitários e pesados sendo caminhões, ônibus, e excepcionalmente moto, devido o nível de pressão sonora produzido) é possível verificar a relação direta entre o nível de pressão sonora medida em $\mathrm{dB}(\mathrm{A})$ com o volume de tráfego (Figura 10).

Considerando os cenários das variáveis condicionantes da demanda anteriormente apresentadas e os modelos de simulação e análise de transportes desenvolvidos para o Plano diretor de Transporte Metropolitano, foram estimadas as demandas de viagens futuras, entre pares de zonas origem e destino, para o transporte coletivo e individual para os anos horizontes de 2012, 2017 e 2027. A Tabela 1 mostra as projeções de viagens no período de pico da manhã para a Região Metropolitana de Natal, para o transporte coletivo e para o transporte individual.

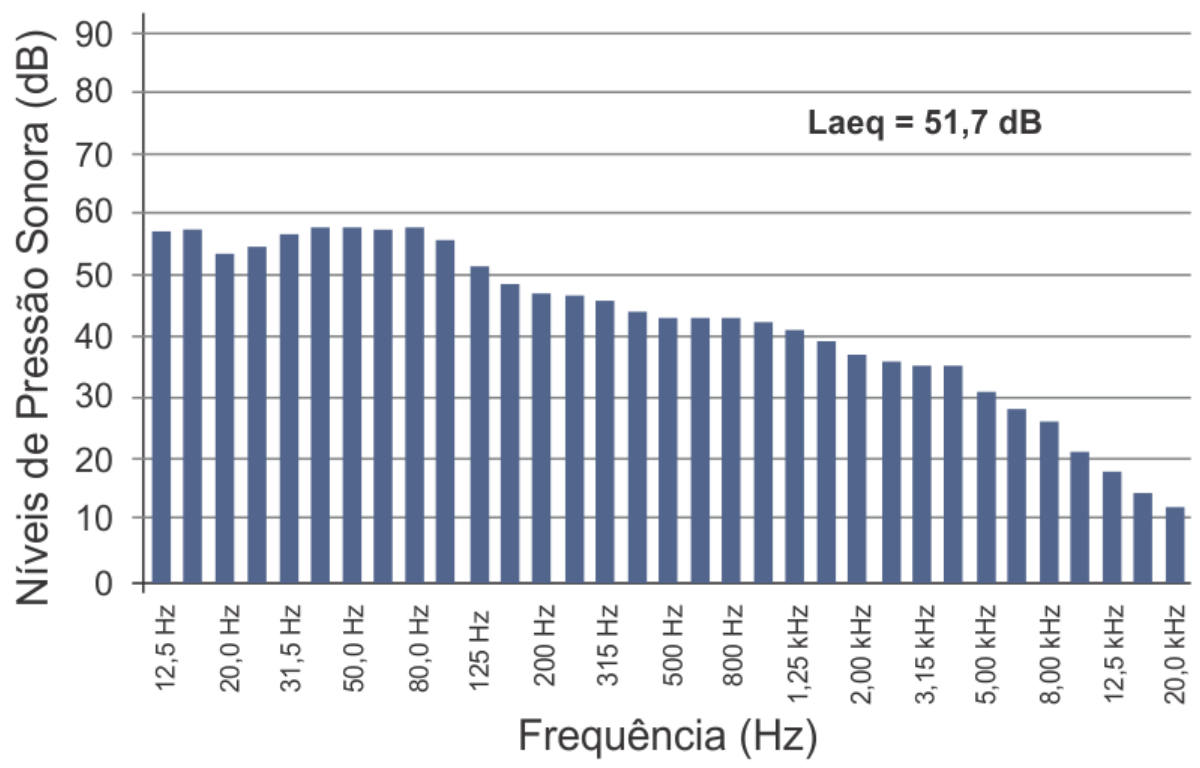

Figura 8: Nível de Pressão Sonora por frequência (medição de menor LAeq)

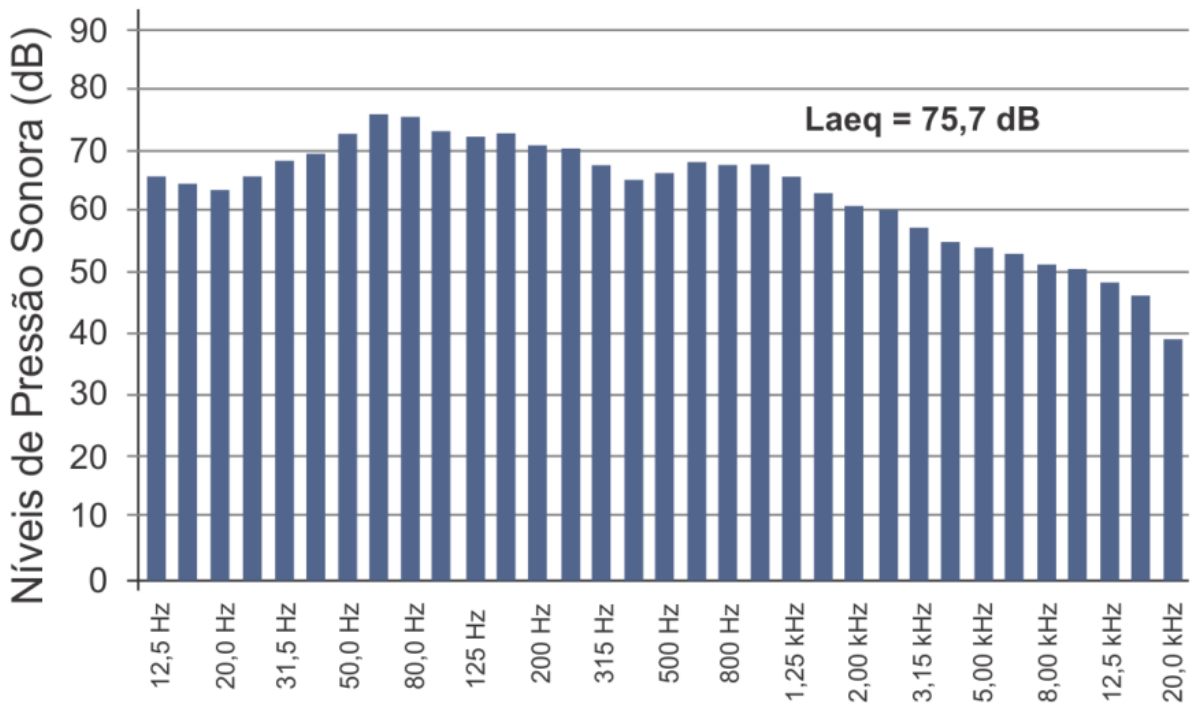

Frequência $(\mathrm{Hz})$

Figura 9: Nível de Pressão Sonora por frequência (medição de maior LAeq) 


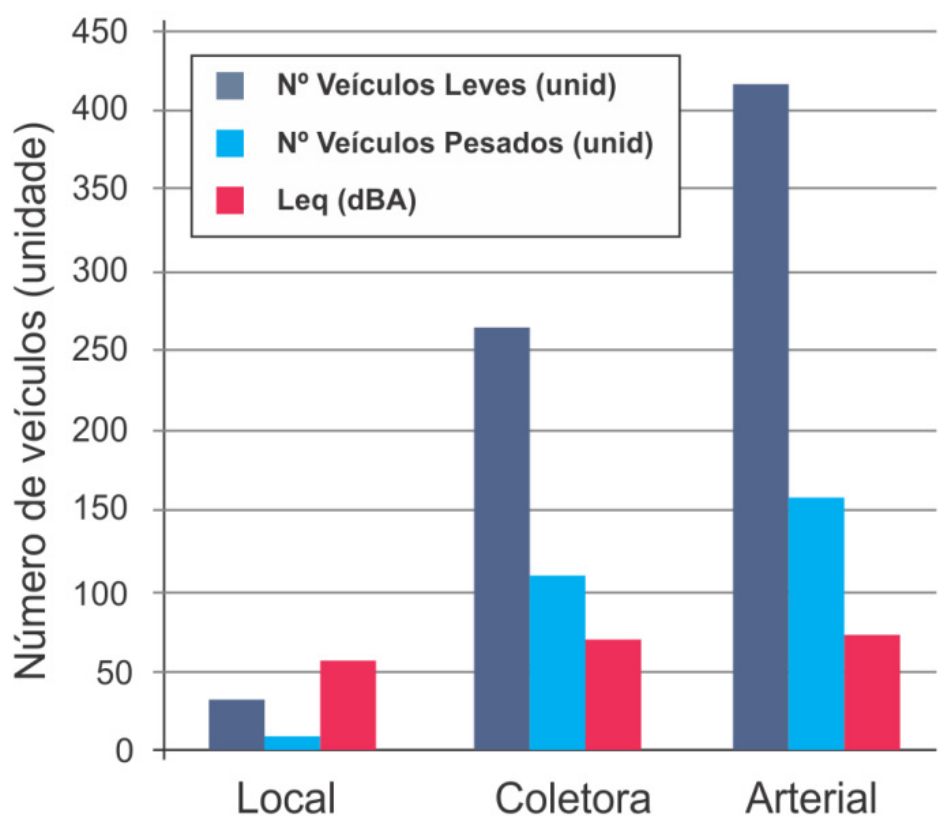

Figura 10: Relação entre contagem classificada de veículos (leves e pesados) e nível sonoro, por tipologia de via.

\begin{tabular}{|ccccccccccc|}
\hline \multicolumn{2}{c}{ Tabela 1: Evolução das viagens por transporte coletivo e individual nos anos horizontes } \\
para a Hora Pico Manhã - Região Metropolitana de Natal.
\end{tabular}

No Plano Diretor de Transporte Metropolitano da Região Metropolitana do Natal-RN - PDTM/RMN (SINRN, 2008) mostra que a frota de veículos na cidade subirá de 251.968 em 2012 para 321.130 em 2007. Verificou-se, também, que o crescimento das viagens por transporte coletivo será de $36 \%$ e de $74 \%$ por transporte individual até o ano de 2027. Este fenômeno certamente trará maiores impactos no sistema viário e a previsão é que o tempo dentro do veículo aumente e a velocidade diminua devido à falta de estrutura urbana que não suporta o crescimento da cidade. Além dos veículos e população local, valores de pico irão surgir com eventos, como é no caso da copa de futebol FIFA em 2014. Também foi realizado um estudo em que estimaram as demandas de viagens futuras para o transporte coletivo e individual nos anos de 2012, 2017 e 2027. A Figura 11 apresenta o carregamento apenas dos transportes individuais, destacando Lagoa Nova, em 2012 e 2027, no horário de pico da manhã, caso seja utilizado a "Alternativa Nada a Fazer". Esta alternativa não prevê intervenções físicas no sistema viário e administra o crescimento da demanda de transporte coletivo, consistindo basicamente na manutenção e continuidade da configuração da rede em termos físicos e tecnológicos. O bairro de Lagoa Nova está localizado numa zona de intenso tráfego e já apresenta muitos pontos instáveis e alguns saturados, agravando a situação em 2027. 


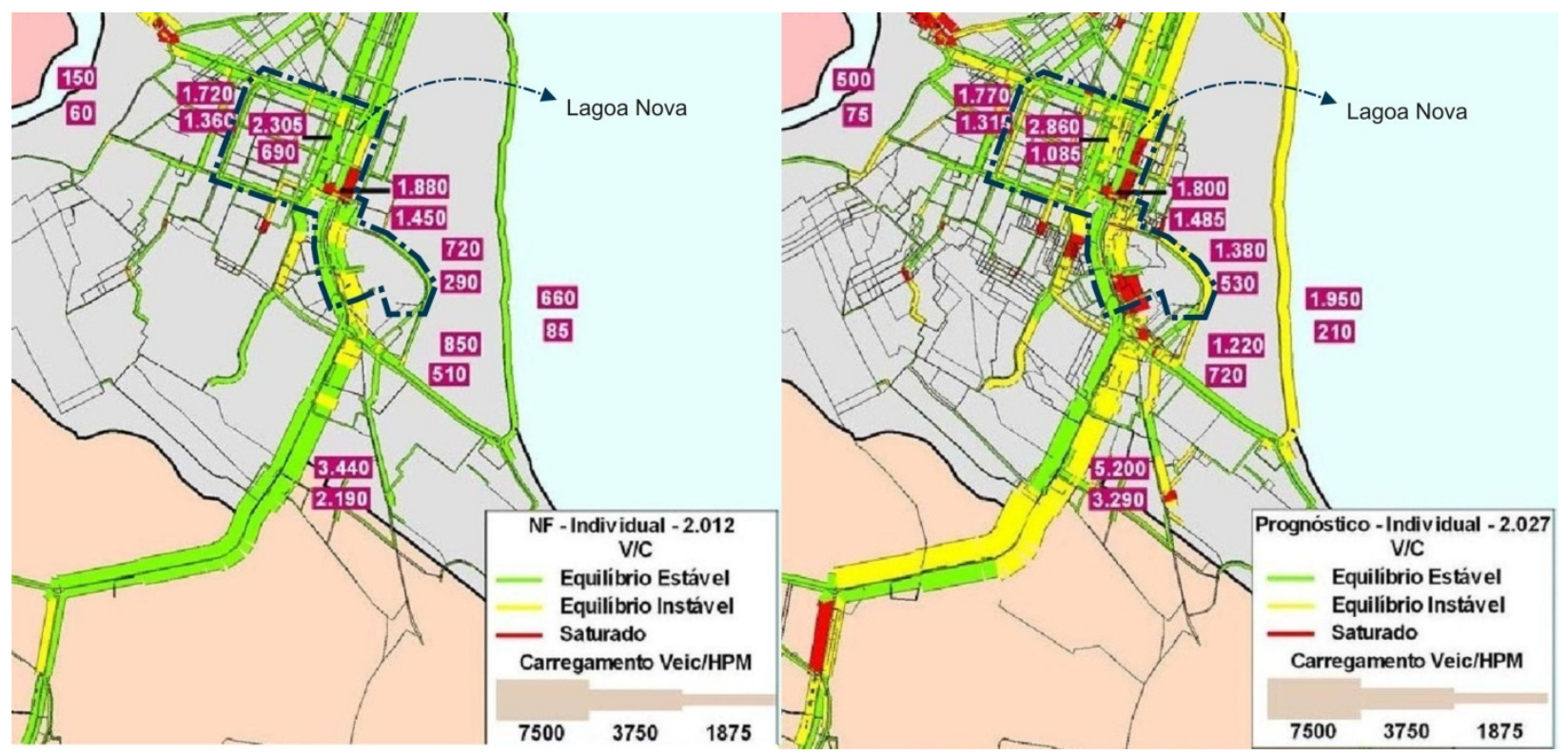

Figura 11: Carregamento de transportes individuais - "Nada a Fazer", 2012 e 2027, respectivamente, no horário de pico da manhã. Fonte: SIN-RN, 2008, modificado.

Percebe-se, assim, que os níveis de ruído estão atualmente acima do recomendado pela norma, na maioria dos pontos medidos e com a tendência de saturação do fluxo de veículos dessas principais. $E$ também nos horários que foram feitas as medições, já existe uma saturação viárias e estudos de previsão de tráfego (SIN-RN, 2008) revelam que para as avenidas arteriais e coletoras, a área possui tendência de saturação.

\section{CONCLUSÕES}

Por meio de uma análise do espaço urbano, notadamente do ponto de vista acústico, pode-se identificar os principais componentes que influenciam no ruído urbano, verificar as fontes sonoras, detectar quais áreas precisam de tratamento, e o que pode ser feito para melhorar a qualidade sonora do ambiente construído.

Em relação à área objeto de estudo foi possível perceber que a maioria dos pontos onde foram realizadas as medições apresentou níveis acima do recomendado pela ABNT NBR 10151(2000), havendo também diferenças significativas do nível de pressão sonora no período diurno e noturno.

Os dados revelaram correlação fortemente positiva entre o volume de tráfego e o Leq (dBA) medido, e consequentemente as vias arteriais carecem de maior preocupação com a questão da poluição sonora. Foi também verificado que com relação ao volume de veículos, já existem áreas de equilíbrio instável, e tendência de saturação para a área objeto de estudo em anos posteriores. Percebe-se, desta forma, que as vias arteriais carecem de uma série de tratamento para uma melhoria da qualidade acústica da região, devido ao frágil e saturado transporte viário na área objeto de estudo.

Com as questões referentes à acústica do espaço urbano, parece que foi assumida a premissa de que nas cidades, devido à necessidade do tráfego de veículos, o ruído é inevitável e que nada pode ser feito. Porém, diversos estudos demonstram que existem ferramentas de mapa de ruído, e instrumentos de traçado urbano e barreiras acústicas com enorme potencial para reduzir o impacto sonoro no meio urbano.

\section{AGRADECIMENTOS}

A equipe de bolsistas da pesquisa de poluição sonora pelo levantamento de dados a campo.

\section{REFERÊNCIAS BIBLIOGRÁFICAS}

ASSOCIAÇÃO BRASILEIRA DE NORMAS TÉCNICAS (ABNT). NBR 10.151: Avaliação do nível do ruído em áreas habitadas visando o conforto da comunidade. Rio de Janeiro, 2000.

BISTAFA, S.. Acústica aplicada ao controle de ruído. São Paulo: Edgard Bugher, 2006.

KATZCHNER, I. Urban climate studies as tools for urban planning and architecture. In: Encontro Nacional sobre Conforto no Ambiente Construído, IV, 1997, Salvador. Anais... Salvador, p. 49-58. 1997 
MACEDO, Maria Eleonora Silva. Análise da interferência da legislação urbanística no crescimento do bairro de Lagoa Nova: planos diretores de 1974, 1984, 1994. Dissertação (mestrado). Universidade Federal do Rio Grande do Norte. Programa de Pós-graduação em Arquitetura e Urbanismo. Natal, 2005.

MARCELO, C. B. Sons e Formas: As barreiras acústicas na atenuação do ruído na cidade. Dissertação de Mestrado em Arquitetura e Urbanismo. Universidade Presbiteriana Mackenzie, São Paulo, 2006.

MÉNDEZ, et AL. Acustica Arquitectonica. Universidade Del Museo Social Argentino. Buenos Aires, 1994.

MOTA, Suetônio. Planejamento Urbano e Preservação Ambiental. Universidade Federal do Ceará: Proedi, 1981.

SEUTÔNIO, Mota. Planejamento Urbano e Preservação Ambiental. Fortaleza, CE: PROEDI UFC, 1981.

PINTO, Fernando A. N. C.; MORENO, Maysa D. Mapa de ruido de barrios densamente poblados: Ejemplo de Copacabana, Rio de Janeiro - Brasil. VI Congresso Iberoamericano de Acústica FIA 2008. Buenos Aires, 2008.

SANCHO, V. Mestre; SENCHERMES, A. Garcia. Curso de ACUSTICA. Colégio Oficial de Arquitectos de Madrid: Madrid,1983.

SIN /RN - SECRETARIA DE INFRA-ESTRUTURA DO ESTADO DO RIO GRANDE DO NORTE. Plano Diretor de Transporte Metropolitano da Região Metropolitana do Natal-RN. Relatório Síntese: Oficina, Natal, 2008.

SEMURB - SECRETARIA MUNICIPAL DE MEIO AMBIENTE E URBANISMO. Conheça melhor o seu bairro: Lagoa Nova. Natal, 2008. Disponível em <http://www.natal.rn.gov.br/semurb/ paginas/ctd-102.html> Acessado em 25 de fevereiro de 2013. 